\title{
Stem and Progenitor Cells: Origins, Phenotypes, Lineage Commitments, and Transdifferentiations
}

Irving L. Weissman

B257 Beckman Center, Stanford University School of Medicine Stanford, California 94305-5323; e-mail: Irv@stanford.edu

\author{
David J. Anderson \\ Division of Biology, 216-76, California Institute of Technology Pasadena, \\ California 91125; e-mail:Wuwei@caltech.edu \\ Fred Gage \\ The Salk Institute, Laboratory of Genetics 10010 N. Torrey Pines Road, \\ La Jolla, California 92037; e-mail: Gage@salk.edu
}

Key Words stem cells, progenitors, multipotent, transdifferentiation

- Abstract Multipotent stem cells are clonal cells that self-renew as well as differentiate to regenerate adult tissues. Whereas stem cells and their fates are known by unique genetic marker studies, the fate and function of these cells are best studied by their prospective isolation. This review is about the properties of various highly purified tissue-specific multipotent stem cells and purified oligolineage progenitors. We contend that unless the stem or progenitor cells in question have been purified to near homogeneity, one cannot know whether their generation of expected (or unexpected) progeny is a property of a known cell type. It is interesting that in the hematopoietic system the only long-term self-renewing cells in the stem and progenitors pool are the hematopoietic stem cells. This fact is discussed in the context of normal and leukemic hematopoiesis.

\section{CONTENTS}

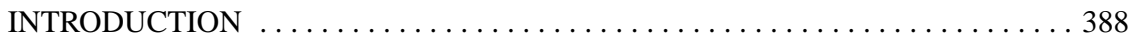

HEMATOPOIETIC STEM CELLS AS THE MODEL $\ldots \ldots \ldots \ldots \ldots \ldots \ldots . \ldots . \ldots 38$

IDENTIFICATION AND ISOLATION OF HEMATOPOIETIC

PROGENITOR CELLS . . ................................. 390

SELF-RENEWAL, STEM CELLS, AND CANCER $\ldots \ldots \ldots \ldots \ldots \ldots \ldots \ldots \ldots . \ldots \ldots$

CENTRAL NERVOUS SYSTEM (CNS) STEM CELLS . ................ 392

IDENTIFICATION AND ISOLATION OF PERIPHERAL NERVOUS

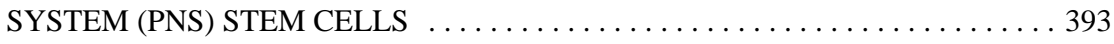




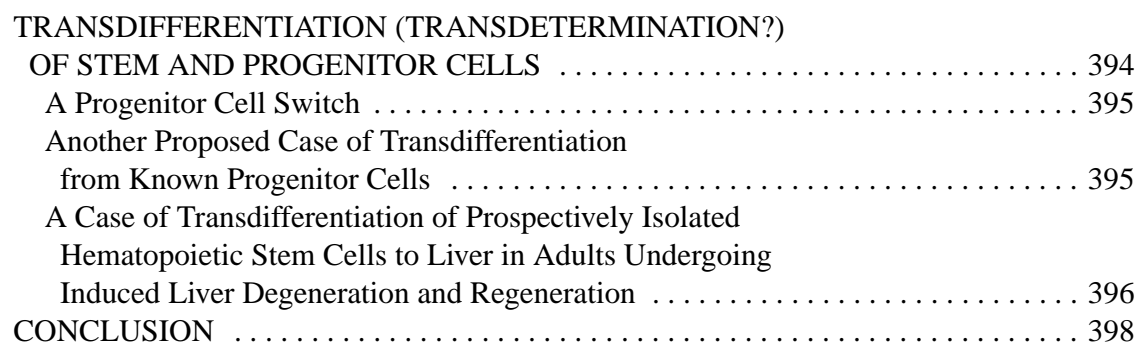

\section{INTRODUCTION}

Significant attention has been directed toward research in the general area of stem cells. Although the level of activity is high, there is considerable confusion and disagreement among investigators as to the properties of stem cells. Part of the confusion can be traced to the different definitions that are used to define stem cells, the methods and procedures used to characterize the starting population, and the state of populations of cells that are evaluated. In this review, we first take an historical perspective, emphasizing the rationale for the requirement of clonogenic assays in defining a stem cell, with special reference to the hematopoietic system. We next describe how this approach can be extended to other lineages such as nervous system tissues. With this background, we take up a current area of controversy in stem cell biology - that of transdifferentiation and/or dedifferentiation-and describe how a clonogenic approach to stem cell identification can help to defuse or untangle the current debate.

\section{HEMATOPOIETIC STEM CELLS AS THE MODEL}

Stem cells are currently defined as single cells that are clonal precursors of both more stem cells of the same type, as well as a defined set of differentiated progeny (for reviews, see Gage 2000; Weissman 2000a,b). The first genetic evidence that stem cells exist came from the studies of Till, McCulloch, Wu, Becker, and Siminovitch on blood-forming (hematopoietic) stem and progenitor cells (Till \& McCulloch 1961). In these experiments, random chromosome markers were generated in donor bone marrow by radiation, and colonies of progeny cells, each derived from a single clonogenic precursor, were found in the spleens of conditioned hosts; these colonies always contained differentiated cells of the myeloerythroid series and often contained cells that could be used to reconstitute secondary hosts to produce all blood cell lineages (Becker et al. 1963, Wu et al. 1968). Although the concept of stem cells has been extended to many other tissues, it is our contention that only rarely have stem cells been identified as clonogenic precursors that include in their progeny both self-renewed stem cells and differentiated progeny. Just as genetics provides evidence for the nature of a particular event, it does not 
provide for the purification of the gene, the gene product, or in this case the stem cell that genetic evidence implied. Although biochemistry is the discipline that has provided purification of genes and molecules, a new field of cellular purification was required to allow the prospective isolation of stem and progenitor cells.

To provide for the first isolation of mouse hematopoietic stem cells (HSC), it was necessary to develop assays for the clonal precursors of all known differentiated blood cell types, including myeloerythroid cells (Till \& McCulloch 1961), B lineage cells (Muller-Sieburg et al. 1986, Whitlock et al. 1987), and T lineage cells (Ezine et al. 1984). The second step required for the isolation of HSC was the production of monoclonal antibodies to cell surface molecules found on bone marrow cells. The third requirement was for high-speed sorting of cells bearing and lacking combinations of monoclonal antibody-defined surface determinants (Muller-Sieburg et al. 1986, Spangrude et al. 1988).

An important step in the isolation of HSC was the finding that the clonogenic precursors in all three of the above assays were contained within the population of cells that lacked or had only very low levels of markers of lineage commitment to various blood cell types (Muller-Sieburg et al. 1986). Thus HSC are lineage negative $\left(\mathrm{Lin}^{-}\right)$for markers found on T cells, B cells, granulocytes, monocytes/macrophages, erythroid cells, natural killer cells, etc. Mouse HSC are positive for two cell surface glycophosphatidyl inositol-linked immunoglobulin superfamily molecules, Sca-1 (Ly6A/E) and Thy-1 (Spangrude et al. 1988). They are also positive for the c-kit receptor tyrosine kinase (Ikuta \& Weissman 1992), although in instances in which endogenous or exogenous c-kit ligand (SLF) is abundant, the c-kit marker is partially down-modulated. These c-kit ${ }^{+}(\mathrm{K})$, Thy-1.1 ${ }^{\text {lo }}(\mathrm{T}), \mathrm{Lin}^{-/ \mathrm{lo}}(\mathrm{L}), \mathrm{Sca}-1^{\mathrm{hi}}(\mathrm{S})$, bone marrow (BM) cells are, at the clonal level, all multipotent, but can be subdivided into three subpopulations by surface markers and by degree of self-renewal (Morrison \& Weissman 1994): (a) The totally $\mathrm{Lin}^{-}$subset (many but not all of which are $\mathrm{CD} 34^{\mathrm{lo}}$ ) consists of perpetually self-renewing long-term (LT) HSC. (b) The Mac-1 ${ }^{\text {lo }}$ subset of KTLS cells is a uniform population of multipotent cells that self-renew in vivo upon transplantation for $\sim 6$ weeks, which is the end of their productive lifespan (ST-HSC). (c) The Mac- $1{ }^{\text {lo }} \mathrm{CD} 34^{\text {lo }}$ subset of KTLS are clonogenic multipotent precursors whose self-renewal potential is short and, under transplant conditions difficult to detect; these cells are called multipotent progenitors (MPP). LT-HSC give rise to ST-HSC, which in turn give rise to MPP, and we cannot detect dedifferentiation in that lineage (Morrison et al. 1997a). That is, ST-HSC never give rise to LT-HSC, and MPP never give rise to either LT-HSC or ST-HSC. KTLS cells can be mobilized from BM to blood; treatment of a donor with cytoxan plus G-CSF causes all HSC to enter the cell cycle, and many daughter HSCs are released to the blood (Morrison et al. 1997b).

KTLS cells are the only cells within mouse BM that will both radioprotect and reconstitute all blood cell lineages (Uchida \& Weissman 1992). Increasing the dose of KTLS cells transplanted into lethally irradiated hosts shortens the time to the appearance of donor-derived blood cells and elements; however, in the 
syngeneic (transplant of cells between mice of the same strain) setting, increasing the dose even 10-fold above that required for engraftment by 10 days neither shortens the time to engraftment further nor has any attendant toxicities (Uchida et al. 1998). These experiments provide two important points for the kind of regenerative medicine that will result from stem cell therapies; first, only stem cells (even LT-HSC) are required for rapid engraftment and, second, the body regulates the cellular output from transplanted HSC. Even in lethally irradiated mice there are immune barriers to the transplantation of HSC from genetically different, allogeneic donors. For example, the minimal HSC dose to just radioprotect $95 \%$ of irradiated hosts is 100 cells in the syngeneic setting, about 500 cells in major histocompatibility complex (MHC) -matched but otherwise unmatched donorrecipient combinations, and 1-3000 HSC in a variety of donor host combinations that are neither MHC nor otherwise matched (Shizuru et al. 1996). Because HSC lack contaminating $\mathrm{T}$ lymphocytes, these allogeneic chimeras do not suffer the consequences of a $\mathrm{T}$ cell-mediated graft versus host $(\mathrm{GvH})$ response (Shizuru et al. 1996). These allogeneic chimeras are also specifically tolerant for the life of organ, tissue, or other tissue-specific stem cell transplants from the HSC genotype donor (Gandy \& Weissman 1998, Shizuru et al. 2000).

Human HSC have been isolated from umbilical cord blood, fetal liver, fetal bone marrow, adult bone marrow, and mobilized peripheral blood (MPB). These cells are CD34 ${ }^{+}$, Thy- $1^{+}, \mathrm{Lin}^{-}$, c-kit ${ }^{\mathrm{l}}$, and CD38- (Baum et al. 1992, Tsukamoto et al. 1995), although there are some indications that in humans there is also a rare $\mathrm{CD} 34^{-/ \mathrm{lo}}$ subset of this general population that has HSC activity. Prospective isolation of $\mathrm{CD}_{34}{ }^{+} \mathrm{Thy}^{+}$cells is an efficient method of purifying them away from cancer cells present in the MPB (Negrin et al. 2000). Successful transplantation of cancer-depleted or cancer-deficient MPB HSC has resulted in donor-derived rescue of fully myelo-ablated cancer patients (stage IV breast cancer, non-Hodgkin's lymphoma, multiple myeloma) in the same dose- dependent fashion that KTLS cells provided in mouse studies (Michallet et al. 2000, Negrin et al. 2000).

\section{IDENTIFICATION AND ISOLATION OF HEMATOPOIETIC PROGENITOR CELLS}

The same methodology that allowed prospective isolation of mouse HSC has been used to identify and isolate mouse hematopoietic oligolineage progenitors (Akashi et al. 2000, Kondo et al. 1997). As shown in Figure 1, downstream of the clonogenic multipotent pool are two developmental choices, either the common myeloid progenitor (CMP) or the common lymphocyte progenitor (CLP). Each of these cell types has been isolated to homogeneity, each is a clonal precursor of a limited subset of progeny, and each has a distinct expressed gene profile (Akashi et al. 2000; Metcalf 1989, 1991). Two kinds of cytokine cell surface receptors are good markers of the commitment to the myeloid or the lymphoid pathway: CMP, like HSC, express granulocyte macrophage cell-stimulating factor receptors 
(GM-CSFR) and do not express cell surface IL-7 receptor, whereas CLP express cell surface IL-7R $\alpha \gamma_{c}$ but do not express GM-CSFR (Kondo et al. 1997). Each CMP can give rise to even more lineage-restricted progenitors, either the granulocyte/monocyte progenitor (GMP) or the megakaryocyte/erythrocyte progenitor (MEP). Under normal conditions, these cells are absolutely lineage restricted and upon transplantation do not detectably self-renew (Kondo et al. 1997). They must, therefore, be derived continually from HSC, and in the steady state, all HSC (including LT-HSC) will enter the cell cycle in a regulated fashion (Cheshier et al. 1999). For example, $8 \%$ of the LT-HSC enter the cell cycle per day at random, whereas higher percentages of ST-HSC, MPP, CLP, and CMP enter the cell cycle each day (Morrison \& Weissman 1994, Kondo et al. 1997, Akashi et al. 2000, Cheshier et al. 1999). The GMP and MEP progeny of CMP are also virtually all in cell cycle (Akashi et al. 2000). Following a variety of stimuli, all LT-HSC can enter the cell cycle in vivo in largely self-renewing divisions (Morrison et al. 1997b, Wright et al. 2001). However, in vitro expansion of KTLS HSC and their subsets by self-renewal has not yet been reliably accomplished.

\section{SELF-RENEWAL, STEM CELLS, AND CANCER}

It is important to note that long-term self-renewal is limited to LT-HSC in the hematopoietic stem and progenitor pool. Despite intense investigation, genetic control of self-renewal and LT-HSC expansion remains a mystery. It is also important to note that all mouse leukemias, no matter what stage of differentiation marks the leukemogenic stem cell, have also gained the properties of self-renewal, as have all other clonogenic cancer cells. It is crucial, therefore, to define the genetic control of self-renewal in this class of stem cells, as well as the leukemias derived from their progeny.

There are several important points about the fact that normally only stem cells self-renew perpetually and that leukemias and cancers contain leukemic (Bonnet \& Dick 1997) and cancer stem cells that have gained (or retained) the property of self-renewal. Several leukemias contain leukemia-specific chromosomal translocations, deletions, amplifications , or inversions (e.g., Miyamoto et al. 2000, Fialkow et al. 1991, Seale et al. 1996, Faderl et al. 1999, Hagemeijer et al. 1984). In many of these leukemias, the critical chromosomal aberration is in the HSC pool, varying from a fraction to all HSC. Yet in many of these cases, the HSC are not malignant (Miyamoto et al. 2000). We have proposed that although in acute myelogenous leukemia the translocation (AML-1; ETO) is in HSC, the final steps in leukemia progression have occurred downstream of HSC (Miyamoto et al. 2000). This makes sense. If HSC are the only hematopoietic cells that normally self-renew, then the only genetic alterations in leukemia progression that can be retained in the hematopoietic system must accumulate in HSC, until one or more events permit a downstream progenitor class to self-renew. After that, both self-renewing populations can accumulate transforming mutations. The result, presumably true for all malignancies and not just leukemias, is that either the normal stem cell class or a 
downstream cell (Miyamoto et al. 2000, Bonnet \& Dick 1997) could gain the ultimate stage of malignant progression. In one case, the malignancy is in stem cells, and in the other, a downstream progenitor is transformed to the cancer stem cells.

An additional point is that within a leukemia or a cancer, the cancer stem cell may not exclusively self-renew but may simply increase the frequency of self-renewing divisions. The consequence of this possibility is that the cancer/leukemia stem cell could be a minority of cells in the lesion and in its clone. Given this possibility, it will be essential to identify and isolate the malignant stem cell for each type of malignancy because only this cell has the critical gene expression profile of the true cancer cell or the critical tumor antigens against which effective immunity must be directed.

\section{CENTRAL NERVOUS SYSTEM (CNS) STEM CELLS}

Although the conventional wisdom has been that regeneration of brain cells cannot occur after a certain age, the pioneering experiments of Altman (Altman 1962, Altman \& Das 1965), Alvarez-Buylla (Lois \& Alvarez-Buylla 1993, 1994), Bartlett (Kilpatrick \& Bartlett 1993, 1995), Goldman \& Nottebohm (1983), and Gage (Gage 2000, Kuhn et al. 1997, Kempermann et al. 1997, Eriksson et al. 1998) have demonstrated regions of continued high-rate neurogenesis throughout life in rodents and humans. These regions include the subventricular zones (SVZ) bordering (at least) the lateral ventricles and the dentate gyrus (DG) in the hippocampus (Gage 2000). Although it is conceivable that low-rate proliferation might occur in adult brains in different regions, the evidence is not yet in. The methodologies that led to an understanding that CNS stem cells must exist and therefore could be prospectively isolated began with the demonstration that cells derived from rodent fetal brain or adult SVZ or adult DG cells can grow in vitro in the presence of defined factors such as bFGF and EGF (Reynolds \& Weiss 1992, Richards et al. 1992, Temple \& Alvarez-Buylla 1999, Temple \& Davis 1994, Gritti et al. 1996, Johe et al. 1996, Kalyani et al. 1997, Mayer-Proschel et al. 1997, Ray et al. 1993, Davis \& Temple 1994). These cells can grow as adherent monolayers or as non-surface adherent but self-associating neurospheres (Reynolds \& Weiss 1992, Temple \& Alvarez-Buylla 1999, Temple \& Davis 1994, Gritti et al. 1996, Ray et al. 1993, Davis \& Temple 1994). Embryonic stem (ES) cell cultures have been used as a source of subsets of CNS-committed cultures (Brustle et al. 1998, 1999). Retroviral marking of adherent rodent brain cell cultures revealed the presence of clonally marked cells that can both self-renew and give rise to neurons, astrocytes, and oligodendrocytes (Palmer et al. 1997). Transplantation of these clonally marked rodent brain cell cultures into the hippocampus or into the subventricular zone (SVZ) or even into the newborn rat eye has revealed that these cells might include a population of CNS stem cells capable of responding to local microenvironmental cues (Gage 2000; Brustle et al. 1998, 1999; Flax et al. 1998; Morshead et al. 1994; Johansson et al. 1999; Snyder 1994; Reynolds \& Weiss 1996). When it was found that human fetal brain cells could also respond to these growth factors by forming neurosphere 
cultures (Carpenter et al. 1999), the possible existence of a neurosphere-initiating stem cell was proposed (Uchida et al. 2000). Using the same methodologies of clonogenic assays (the neurosphere-initiating cells), i.e., the production and use of cell surface monoclonal antibodies to cell surface determinants and high-speed fluorescent-activated cell sorting (FACS), led to prospective isolation of candidate human fetal brain CNS stem cells (Uchida et al. 2000). Neurospheres derived from $\mathrm{CD} 133^{+}, \mathrm{CD} 24^{-/ \mathrm{lo}}, \mathrm{CD} 34^{-}, \mathrm{CD} 45^{-} \mathrm{c}^{-\mathrm{kit}^{-}}$candidate $\mathrm{CNS}$ stem cells could be dissociated and transplanted into the lateral ventricles of genetically immunodeficient newborn NOD-SCID mice (Uchida et al. 2000). The newborn mouse brain is obviously still undergoing much neurogenesis, and so one could hope that the engrafted cells would participate in such neurogenesis. In fact, robust engraftment was seen for the life of the recipients. In both the SVZ and DG, even 7 months later, human cells, similar to their mouse counterparts, were significantly engaged in continued cell proliferation evidenced by their expression of the proliferationspecific marker Ki67. In zones where mouse cells were migrating away from the sites of proliferation, human cells were found for as long as 7 months or more, where they could be followed, differentiating en route. In zones where mouse cells had differentiated into neurons and glia, human cells also showed morphological evidence of having differentiated into neurons and glia. Standard histological examination of these chimeric mouse brains showed no easily detectable abnormalities such as proliferative or neoplastic cell foci or mal-development. In addition, the progeny of these cells could be found throughout the mouse brain, including the corpus callosum, the striatum, the mid-brain, the cerebellum, and even the cerebral cortex. Injection of similar neurospheres into the SVZ or DG of adult immunosuppressed rats had also been shown to result in site-specific and apparently appropriate human cell proliferation, cell migration, and cell differentiation (Fricker et al. 1999). Gene modification of these adherent cells (Palmer et al. 1997) and neurosphere cultures has been demonstrated; it is reasonable to propose that if gene modification of CNS stem cells in vitro leads to appropriately regulated gene expression upon transplantation, this will add a potent new tool to the armamentarium of stem cell biologists, developmental biologists, and neurobiologists who wish to study the development and function of rodent and human brain cells (reviewed in Anderson 2001). It also is to be expected that by using the techniques described above for the identification of downstream hematopoietic oligolineage progenitors, one should be able to begin to identify and place in lineages both human and rodent CNS progenitors of the major lineages and sublineages.

\section{IDENTIFICATION AND ISOLATION OF PERIPHERAL NERVOUS SYSTEM (PNS) STEM CELLS}

Using in vitro assays for the outcome of differentiation of neural crest cells, Anderson et al. sought the phenotype of PNS stem cells (Stemple \& Anderson 1992). The vertebrate fetal neural crest gives rise to cells that contribute to all head 
structures, as well as to the peripheral nervous system, the adrenal medulla, most if not all smooth muscle cells, melanocytes, and the visceral nervous system (Anderson et al. 2001). Cultured populations of neural crest-derived cells contained a subset of $\mathrm{P}^{+} \mathrm{PO}^{-}$PNS stem cells capable of multilineage maturation. Such cells could be prospectively isolated from the fetal neural crest as well as from late fetal tissues, such as rodent sciatic nerve, using similar markers, and could be shown to be self-renewing clonogenic precursors of peripheral neurons, glia (Schwann cells), and smooth muscle cells (Morrison et al. 1999). Amazingly, rat PNS-SC can be transplanted to chick embryos, where they retain their PNS developmental fates, apparently in response to microenvironmental cues that may be evolutionarily conserved (White \& Anderson 1999, White et al. 2001). Instructive differentiation factors for each of these differentiated derivatives have been identified: GMP2 for autonomic neurons, TGF $\beta$ for smooth muscle cells, and Nrg-1 and Notch for Schwann cells (Shah et al. 1994, 1996; Shah \& Anderson 1997; Morrison et al. 2000). It is not clear whether such neural crest stem cells can give rise to all classes of PNS neurons, e.g., sensory as well as autonomic neurons. Similarly, it is not clear whether multipotent CNS progenitors of neurons, astrocytes, and oligodendrocytes can generate all classes of CNS neurons.

\section{TRANSDIFFERENTIATION (TRANSDETERMINATION?) OF STEM AND PROGENITOR CELLS}

Many recent publications have claimed direct demonstration of transdifferentiation of cells of one type of commitment to stem cells or differentiated cells for distinct organs or tissues (Ferrari et al. 1998; Bjornson et al. 1999; Gussoni et al. 1999; Gritti et al. 1996; Clarke et al. 2000; Brazelton et al. 2000; Mezey et al. 2000; Pereira et al. 1995; Petersen et al. 1999; Theise et al. 2000a,b). Before we examine these data more closely, it is important to establish the minimum criteria for transdifferentiation of stem cells (Morrison 2000; Anderson et al. 2001). Stem cells are clonogenic cells capable of self-renewal and differentiation. Any claim for transdifferentiation must begin with clonally identified tissue-specific stem cells and end with isolation of stem cells, progenitor cells, and progeny in the transdifferentiated organ or tissue. Unfortunately, a jargon exists in both the clinical and scientific literature that equates bone marrow or mobilized peripheral blood or umbilical cord blood transplants with HSC transplants. Similarly, a number of investigators define neurospheres as stem cells without demonstrating that there are any stem cells that can be prospectively isolated and then further assume that every cell in the sphere is a stem cell when it is not clear what frequency are stem cells. The BM, a complex tissue, contains a variety of cell types that include cells committed to mesenchymal lineages (Pittenger et al. 1999), others to endothelial outcomes, and still others to hematopoietic outcomes. Thus it is possible to unwittingly have stem cells of one type of tissue, when in fact they could be stem cells from another tissue or cells that are not stem cells at all but have undergone limited morphological 
differentiation similar to cell types in the host organ (Figure 2). We believe that a claim of stem cell differentiation should include marking or isolating prospectively the cell from the donor tissue and demonstrating, at the clonal level, that this a stem cell from the donor, and that such cells have the capacity to repopulate and regenerate stem cells, oligolineage progenitors, and differentiated and functional progeny. It is not sufficient that rare progeny take on the morphological appearance of tissue-specific differentiated cells. It is not sufficient if the repopulating unit is not shown to be a clonogenic stem cell rather than a cluster of interacting yet heterogeneous cells. Given these requirements and the examples described in the legend in Figure 2, it is now appropriate to consider whether stem and/or progenitor cells can be caused to transdifferentiate.

\section{A Progenitor Cell Switch}

Transplantation of mouse CLP into irradiated hosts reveals their ability only to produce all varieties of T cells, B cells, natural killer (NK) cells, and antigen-presenting dendritic cells that do or do not express or express surface CD8 $\alpha$ (Traver et al. 2000). Adult BM CLP have never been shown either in vitro or in vivo to give rise to granulocytes or macrophages (Kondo et al. 1997). However, if one induces in or transfects to CLP, the GM CSF receptor, or genes that can induce the expression of that receptor, these cells can immediately respond by differentiating to granulocytes and macrophages at the expense of generating lymphoid cells, even at the clonal level (Kondo et al. 2000). While this may seem to be a limited transdifferentiation, it is important to note that the morphological, functional, and gene expression profiles of granulocytes and independently of macrophages are dramatically different from those of the above-described lymphoid progeny. Interestingly, culture of CLP in the presence of the lymphoid-specific cytokine IL-7 can, after several days, render them resistant to the rescued transdifferentiation to GM cells (Kondo et al. 2000). During that process, most of these cells in vitro commit to the B cell lineage (Kondo et al. 1997, 2000). Freshly isolated early pro-B cells cannot be transdifferentiated to GM cells, although very early pro-T cell types in the thymus can (Kondo et al. 2000). At the stage of thymic T cell differentiation that correlates to the rearrangement and surface expression of antigen-specific TCR $\alpha \beta$ heterodimers, the cells have become resistant to transdifferentiation to GM cells (A. King, M. Kondo \& I.L. Weissman, in preparation). It appears, therefore, that in normal lineage commitments a phase of lymphoid-specific determination exists wherein the normal outcomes are only of the lymphoid type, but the genome remains sufficiently plastic for further developmental stages to be rescued from one set of phenotypes to another. This might be a general principle.

\section{Another Proposed Case of Transdifferentiation from Known Progenitor Cells}

In rodents, a class of glial progenitors can be isolated from the optic nerve that normally have the ability to produce only oligodendrocytes and some astrocytes 
(Kondo \& Raff 2000). However, when these O2A cultures are exposed to BMP2 or $10 \%$ fetal calf serum and then switched into the type of culture medium that enables the development of neurospheres, these cells, too, can give rise to neurospheres that generate neurons, astrocytes, and oligodendrocytes (Kondo \& Raff 2000). However, in this experiment, it remains possible that a rare subpopulation of bFGF-responsive uncommitted cells are responsible for the trilineage outcome.

\section{A Case of Transdifferentiation of Prospectively Isolated Hematopoietic Stem Cells to Liver in Adults Undergoing Induced Liver Degeneration and Regeneration}

Mice bearing the most common class of mutations found in human hereditary tyrosinemia patients [inactivation of fumaryl acetoacetic hydrolase (FAH)] usually undergo progressive cycles of liver degeneration, regeneration, and the development of hepatocarcinomas (Grompe et al. 1995). This is almost certainly the result of build-up of the tyrosine catabolites succinyl acetoacetic acid and fumaryl acetoacetic acid, which are toxic to both liver and kidney proximal tubules (Grompe et al. 1995). Placing these mice on a tyrosine-free diet and providing them with a drug (NTBC) that blocks the first step of catabolism of tyrosine allows these transgenic mutant mice to survive (Grompe et al. 1995). Reintroduction of a tyrosine-containing diet along with withdrawal of NTBC leads to programmed liver degeneration and death from hepatic failure (Grompe et al. 1995). KTLS HSC from $\mathrm{FAH}^{+} \mathrm{LacZ}^{+}$male CD45 congenic donors were transplanted at limit dilution or at high-cell doses into lethally irradiated $\mathrm{FAH}^{-}$hosts; in the limit dilution case, mice were rescued from hematopoietic failure with female $\mathrm{FAH}^{-} \mathrm{LacZ}^{-} \mathrm{CD} 45$ congenic BM (Lagasse et al. 2000). These KTLS HSC expressed CD45, a molecule found normally only on all blood-forming cells, except mature erythrocytes, and not found on other cell types in the body. When these mice were later placed on tyrosine-containing diets and withdrawn from NTBC for several cycles, $\mathrm{LacZ}^{+} \mathrm{Y}$ chromosome-positive $\mathrm{FAH}^{+}$liver nodules made up of albumin-producing E cadherin-positive hepatocytes were found (Lagasse et al. 2000). Using single-marker depletions and purifications, it was shown that the only cells in mouse BM that could reconstitute donor-derived liver nodules were c-kit ${ }^{+}$ Sca- $1^{+} \mathrm{Lin}^{-}$cells (Lagasse et al. 2000). Transplantation of whole BM from $\mathrm{FAH}^{+}$ $\mathrm{LacZ}^{+}$male mice not only gave rise to donor-derived liver regeneration, but these mice had restored liver function that kept the hosts alive, even in the absence of NTBC (Lagasse et al. 2000). Furthermore, the only mice showing donor-derived hepatopoiesis also showed donor-derived hematopoiesis; no instances of donorderived hematopoiesis or hepatopoiesis alone were recorded (Lagasse et al. 2000). Although the limit dilution experiments here imply that a single clonogenic HSC can in this circumstance give rise to both blood and liver, these experiments need to be carried out with either single-cell KTLS HSC transplants or with randomly marked KTLS cells. 
In this case of liver regeneration, one can say with confidence that KTLS HSC, presumably cells of mesodermal origin, regenerate liver epithelial cells, presumably of endodermal origin. This brings up the question of what is the normal source of liver stem cells during fetal development-KTLS HSC or endodermalcommitted cells? Although it has been demonstrated that endodermal buds transplanted reciprocally between same developmental stage quail and chicks can give rise to donor-derived liver and pancreas, it is not clear whether the stem cell within these endodermal buds are not HSC. In a classic case similar to this one, using fetal thymic transwell cultures, early fetal thymic epithelium cultured with same age thymic or non-thymic mesenchyme produced thymic lymphocytes in the epithelial side (Auerbach 1961). However, later studies demonstrated that within similar dissociated thymic epithelia recently emigrated rare cells of hematopoietic appearance were found and that it was these cells rather than the much more abundant epithelial cells that gave rise to thymic lymphocytes (Moore \& Owen 1967). Rigorous purification of cells in the early embryonic endodermal region must be attempted in order to identify the nature of the cell type or types in the bud that gives rise to the first liver and pancreas cells.

These experiments call into question what we think we know about the embryonic/fetal generation of each organ or tissue and whether the same or different cell types remain for the regeneration of such cells and tissues. Given the robust transdifferentiation capacity of KTLS HSC in at least this case, one must wonder whether KTLS HSC or another multipotent cell is responsible for other reports of transdifferentiations or even of organism cloning from nuclei. Relevant to this proposal is the recent demonstration that MPB KTLS HSC are present in the blood with a residence time of 1-5 min (Wright et al. 2001; A. Wagers, D. Wright \& I.L. Weissman, in preparation). Because several hundred KTLS HSC can be found in normal blood at any time, it is apparent that continual flux of large numbers of HSC from bone marrow to blood to tissues may be occurring every day. Thus isolation of cells from muscle, liver, mammary gland, or even brain must be considered to be potentially contaminated with KTLS HSC. Low-frequency readouts of tissue transdifferentiation or donor nucleus-derived organism cloning might therefore derive not from most resident cells in the tissue but from a rare set of pluripotent or multipotent cells passing through that tissue.

Several other demonstrations of apparent transdifferentiation have been recorded. Perhaps most striking is the demonstration that single cell-derived neurospheres, when transplanted into genetically distinct mouse blastocysts or even into early chick embryos, at very low frequency, give rise to a wide variety of epithelial tissues (Clarke et al. 2000). In another example, neurospheres bearing clonal retroviral markers upon transplantation into sublethally irradiated, fully allogeneic mouse recipients resulted incredibly in a late switch of all hematopoiesis from host to donor (Bjornson et al. 1999). Both of these remarkable experiments should be repeated by independent laboratories, much in the way the KTLS HSC to liver transdifferentiation should be repeated by independent laboratories. 
In another striking experiment, partially enriched $\mathrm{Lin}^{-} \mathrm{Sca}-1^{+}$hematopoietic cells transplanted directly into the dying myocardium of recipients, in which $3-5 \mathrm{~h}$ previously the left anterior descending coronary arteries had been ligated, resulted in robust regeneration of myocardium, endothelium, and endothelial smooth muscle cells from the donor (Orlic et al. 2001). It will be critical to test whether the $\mathrm{Lin}^{-} \mathrm{Sca}^{+} \mathrm{BM}$ cells responsible for these regenerations are $\mathrm{HSC}$ or some other $\mathrm{Lin}^{-} \mathrm{Sca}^{+}$cells, of which there are many types in BM.

In many tissues, a rare subset of cells capable of excluding organic dyes such as rhodamine 123 or Hoechst 33342 from cell cytoplasm (called the side population) can be prospectively isolated and shown to be enriched for progenitors for blood formation or for muscle regeneration (Goodell et al. 1996). The BM side population appears to be highly enriched for, but not entirely composed of, KTLS HSC (Goodell et al. 1996). Side population cells from BM have been reported to regenerate muscle and side population muscle cells to regenerate blood (Gussoni et al. 1999, Jackson et al. 1999). It remains to be determined whether these are cells committed normally to that organ's regeneration, or in the case of muscle origin, are these hematopoietic $\mathrm{CD} 45^{+}$cells and myogenic CD45 cells?

There are many reports of unseparated BM cells that have generated rare cells in the brain or the blood vessels. In these cases, the identity of the cells within the BM responsible for the transdifferentiation is not known, nor are the daughter cells found in different organs yet shown to have functional characteristics of resident mature cells in these organs. Much remains to be done with these types of experimental models.

\section{CONCLUSION}

The advent of stem cell biology has revealed several unexpected principles, including the likelihood that most if not all tissues are generated during fetal life and regenerated in adult life from stem to progenitor to progeny cells. The application of stem cell biology to clinical hematopoietic cell transplantation has allowed massive expansion of the disease indications for such stem cell transplantations, either autologous or allogeneic, in preclinical animal models. Stem cell biology has been applied to human hematopoietic cell transplantation as well, wherein the goal is to allow the physician to use lethal doses of myeloablative drugs in an attempt to kill all endogenous cancer cells thereby rescuing the patients with cancer free HSC. The recent flurry of papers claiming adult regeneration of non-hematopoietic tissues and transdifferentiation and regeneration in these tissues provides great promise that these too will be translated into clinical therapies. But we must require that both the scientists and the translators of such science to clinical medicine refrain from using confusing jargon and that they must be as rigorous in substantiating their claims of stem cell isolation and stem cell transdifferentiation as the highest standard used by fundamental stem cell biologists. 


\section{Visit the Annual Reviews home page at www.AnnualReviews.org}

\section{LITERATURE CITED}

Akashi K, Traver D, Miyamoto T, Weissman IL. 2000. A clonogenic common myeloid progenitor that gives rise to all myeloid lineages. Nature 404:193-19

Altman J. 1962. Are new neurons formed in the brains of adult mammals? Science 135:112728

Altman J, Das GD. 1966. Autoradiographic and histological studies of postnatal neurogenesis. J. Comp. Neurol. 126:337-90

Anderson DJ. 2001. Stem cells and pattern formation in the nervous system: the possible vs. the actual. Neuron. In press

Anderson DJ, Gage FH, Weissman IL. 2001. Can stem cells cross lineage boundaries? Nat. Med. 7:393-95

Auerbach R. 1961. Experimental analysis of the origin of cell types in the development of the mouse thymus. Dev. Biol 3:336-54

Baum CM, Weissman IL, Tsukamoto AS, Buckle A, Peault B. 1992. Isolation of a candidate human hematopoietic stem cell population. Proc. Natl. Acad. Sci. USA 89:2804-8

Becker A, McCulloch E, Till J. 1963. Cytological demonstration of the clonal nature of spleen colonies derived from transplanted mouse marrow cells. Nature 197:452-54

Bjornson CRR, Rietze RL, Reynolds BA, Negli MC, Vescovi AL. 1999. Turning brain into blood: a hematopoietic fate adopted by adult neural stem cells in vivo. Science 283:534-37

Bonnet D, Dick JE. 1997. Human acute myeloid leukemia is organized as a hierarchy that originates from a primitive hematopoietic cell. Nat. Med. 3:730-37

Brazelton TR, Rossi FM, Keshet GI, Blau HM. 2000. From marrow to brain: expression of neuronal phenotypes in adult mice. Science 290:1775-79

Brustle O, Choudhary K, Karram K, Huttner A, Murray K, et al. 1998. Chimeric brains generated by intraventricular transplantation of fetal human brain cells into embryonic rats. Nat. Biotechnol. 16:1040-44

Brustle O, Jones KN, Learish RD, Karram K, Choudhary K, et al. 1999. Embryonic stem cell-derived glial precursors: a source of myelinating transplants. Science 285:754-56 Carpenter MK, Cui X, Hu ZY, Jackson J, Sherman S, et al. 1999. In vitro expansion of a multipotent population of human neural progenitor cells. Exp. Neurol. 158:265-78

Cheshier S, Morrison SJ, Liao X, Weissman I. 1999. In vivo proliferation and cell cycle kinetics of long-term self-renewing hematopoietic stem cells. Proc. Natl. Acad. Sci. USA 96:3120-25

Clarke DL, Johansson CB, Wilbertz J, Veress B, Nilsson E, et al. 2000. Generalized potential of adult neural stem cells. Science 280:1660-63

Davis A, Temple S. 1994. A self-renewing multipotential stem cell in embryonic rat cerebral cortex. Nature 372:263-66

Eriksson PS, Perfilieva E, Bjork-Eriksson Tk, Alborn AM, Nordborg C, et al. 1998. Neurogenesis in the adult human hippocampus. Nat. Med. 4:1313-17

Ezine SV, Weissman IL, Rouse RV. 1984. Bone marrow cells give rise to distinct cell clones within the thymus. Nature 309:629-31

Faderl S, Talpaz M, Kantarjian HM, Estrov Z. 1999. Should polymerase chain reaction analysis to detect minimal residual disease in patients with chronic myelogenous leukemia be used in clinical decision making? Blood 93:2755-59

Ferrari G, Cusella-De Angelis G, Coletta M, Paolucci E, Stornaiuolo A, et al. 1998. Muscle regeneration by bone marrow-derived myogenic progenitors. Science 279:1528-30

Fialkow PJ, Janssen JW, Bartram CR. 1991. Clonal remissions in acute nonlymphocytic leukemia: evidence for a multistep pathogenesis of the malignancy. Blood 77:1415-17 
Flax JD, Aurora S, Yang C, Simonin C, Wills AM, et al. 1998. Engraftable human neural stem cells respond to developmental cues, replace neurons, and express foreign genes. Nat. Biotechnol. 16:1033-39

Fricker RA, Carpenter MK, Winkler C, Greco C, Gates MA, et al. 1999. Site-specific migration and neuronal differentiation of human neural progenitor cells after transplantation in the adult rat brain. J. Neurosci. 19:5990-6005

Gage FH. 2000. Mammalian neural stem cells. Science 287:1433-38

Gandy KL, Weissman IL. 1998. Tolerance of allogeneic heart grafts in mice simultaneously reconstituted with purified allogeneic hematopoietic stem cells. Transplantation 65:295-304

Goldman SA, Nottebohm F. 1983. Neuronal production, migration, and differentiation in a vocal control nucleus of the adult female canary brain. Proc. Natl. Acad. Sci. USA 80:2390-94

Goodell MA, Brose K, Paradis G, Conner AS, Mulligan RC. 1996. Isolation and functional properties of murine hematopoietic stem cells that are replicating in vivo. J. Exp. Med. 183:1797-806

Gritti A, Parati EA, Cova L, Frolichsthal P, Galli R, et al. 1996. Multipotential stem cells from the adult mouse brain proliferate and self-renew in response to basic fibroblast growth factor. J. Neurosci 16:1091-1100

Grompe M, Lindstedt S, Al-Dhalimy M, Kennaway NG, Papaconstantinou J, et al. 1995. Pharmacological correction of neonatal lethal hepatic dysfunction in murine model of hereditary tyrosinaemia type I. Nat. Genet. 10:453-60

Gussoni E, Soneoka Y, Strickland CD, Buzney EA, Khan MK, et al. 1999. Dystrophin expression in the mdx mouse restored by stem cell transplantation. Nature 401:390-94

Hagemeijer A, Garson OM, Kondo K. 1984. Translocation in acute nonlymphocytic leukemia. Cancer Genet. Cytogenet. 11:284-87

Ikuta K, Weissman IL. 1992. Evidence that hematopoietic stem cells express mouse c-kit, but do not depend on steel factor for their generation. Proc. Natl. Acad. Sci. USA 89:1502-6

Jackson KA, Ml T, Goodell MA. 1999. Hematopoietic potential of stem cells isolated from murine skeletal muscle. Proc. Natl. Acad. Sci. USA 96:14482-86

Johansson CB, Momma S, Clarke DL, Risling M, Lendahl U, et al. 1999. Identification of a neural stem cell in the adult mammalian central nervous system. Cell 96:25-34

Johe KK, Hazel TG, Muller T, Dugich-Djordjevic, McKay RD. 1996. Single factors direct the differentiation of stem cells from the fetal and adult central nervous system. Genes Dev. 10:3129-40

Kalyani A, Hobson K, Rao MS. 1997. Neuroepithelial stem cells from the embryonic spinal cord: isolation, characterization, and clonal analysis. Dev. Biol. 186:202-23

Kempermann G, Kuhn HG, Gage FH. 1997. More hippocampal neurons in adult mice living in an enriched enrivonment. Nature 386:493-95

Kilpatrick TJ, Bartlett PF. 1993. Cloning and growth of multipotential neural precursorsrequirements for proliferation and differentiation. Neuron 10:255-65

Kilpatrick T, Bartlett PF. 1995. Cloned multipotential precursors from the mouse cerebrum require FGF-2, whereas glial restricted precursors are stimulated with either FGF-1 or EGF. J Neurosci 15:3653-61

Kondo M, Scherer DC, Miyamoto T, King AG, Akashi K, et al. 2000. Cell-fate conversion of lymphoid-committed progenitors by instructive actions of cytokines. Nature 407:38386

Kondo M, Weissman IL, Akashi K. 1997. Identification of clonogenic common lymphoid progenitor in mouse bone marrow. Cell 91:661-72

Kondo T, Raff M. 2000. Oligodendrocyte precursor cells reprogrammed to become multipotential CNS stem cells. Science 289:175457

Kopen GC, Prockop DJ, Phinney DG. 1999. Marrow stromal cells migrate throughout 
forebrain and cerebellum, and they differentiate into astrocytes after injection into neonatal mouse brains. Proc. Natl. Acad. Sci. USA 98:10711-16

Kuhn HG, Winkler J, Kempermann G, Thai LJ, Gage FH. 1997. Epidermal growth factor and fibroblast growth factor-2 have different effects on neural progenitors in the adult rat brain. J. Neurosci. 17:5820-29

Lagasse E, Connors H, Al-Dhalimy M, Reitsma M, Dohse M, et al. 2000. Purified hematopoietic stem cells can differentiate to hepatocytes in vivo. Nat. Med. 6:1229-34

Lois C, Alvarez-Buylla A. 1993. Proliferating subventricular zone cells in the adult mammalian forebrain can differentiate into neurons and glia. Proc. Natl. Acad. Sci. USA 90:2074-77

Lois C, Alvarez-Buylla A. 1994. Long-distance neuronal migration in the adult mammalian brain. Science 264:1145-48

Mayer-Proschel M, Kalyani AJ, Mujtaba T, Rao MS. 1997. Isolation of lineage-restricted neuronal precursors from multipotent neuroepithelial stem cells. Neuron 19:773-85

Metcalf D. 1989. The molecular control of cell division, differentiation, commitment and maturation in haemopoietic cells. Nature 339:27-30

Metcalf D. 1991. Lineage commitment of hematopoietic progenitor cells in developing blast cell colonies: influence of colonystimulating factors. Proc. Natl. Acad. Sci. USA 88:11310-14

Mezey E, Chandross KJ, Harta G, Maki Ra, McKercher SR. 2000. Turning blood into brain: cells bearing neuronal antigens generated in vivo from bone marrow. Science 290:1779-82

Michallet M, Philip T, Philip I, Godinot H, Sebban C, et al. 2000. Transplantation with selected autologous blood CD34 ${ }^{+}$Thy $1^{+}$ hematopoietic stem cells (HSCs) in multiple myeloma: impact of HSC dose on engraftment, safety, and immune reconstitution. Exp. Hematol. 28:858-70

Miyamoto T, Weissman IL, Akashi K. 2000. AML1/ETO-expressing nonleukemic stem cells in acute myelogenous leukemia with 8;21 chromosomal translocation. Proc. Natl. Acad. Sci. USA 97:7521-26

Moore MAS, Owen JTT. 1967. Experimental studies on the development of the thymus. $J$. Exp. Med. 126:715-26

Morrison SJ. 2000. Stem cell potential: can anything make anything? Curr. Biol. 11:R7-9

Morrison SJ, Perez SE, Zhou Q, Verdi JM, Hicks C, et al. 2000. Transient Notch activation causes an irreversible switch from neurogenesis to gliogenesis by neural crest stem cells. Cell 101:499-510

Morrison SJ, Weissman IL. 1994. The longterm repopulating subset of hematopoietic stem cells is deterministic and isolatable by phenotype. Immunity 1:661-73

Morrison SJ, Wandycz AM, Hemmati HD, Wright DE, Weissman IL. 1997a. Identification of a lineage of multipotent hematopoietic progenitors. Development 124:1929-39

Morrison SJ, White PM, Zock C, Anderson DJ. 1999. Prospective identification, isolation by flow cytometry, and in vivo selfrenewal of multipotent mammalian neural crest stem cells. Cell 96:737-49

Morrison SJ, Wright D, Weissman I. 1997b. Cyclophosphamide/G-CSF induces hematopoietic stem cells to proliferate prior to mobilization. Proc. Natl. Acad. Sci. USA 94:190813

Morshead CM, Reynolds BA, Craig CG, McBurney MW, Staines WA, et al. 1994. Neural stem cells in the adult mammalian forebrain: a relatively quiescent subpopulation of subependymal cells. Neuron 13:1071-82

Muller-Sieburg C, Whitlock CA, Weissman IL. 1986. Isolation of two early B lymphocyte progenitors from mouse marrow: a committed pre-pre-B cell and a clonogenic Thy- $1^{\text {lo }}$ hematopoietic stem cell. Cell 44:653-62

Negrin RS, Atkinson K, Leemhuis T, Hanania E, Juttner C, et al. 2000. Transplantation of highly purified CD $34^{+}$Thy $1^{+}$hematopoietic stem cells in patients with metastatic breast cancer. Biol. Blood Marrow Transplant. 6:262-71

Orlic D, Kajstura J, Chimenti S, Jakoniuk I, 
Anderson SM, et al. 2001. Bone marrow cells regenerate infarcted myocardium. $\mathrm{Na}$ ture 410:701-5

Palmer T, Takahasi J, Gage FH. 1997. The adult rat hippocampus contains primordial neural stem cells. Mol. Cell Neurosci. 8:389404

Pereira RF, Hatford KW, O'Hara MD, Leeper DB, Sokolov BP, et al. 1995. Cultured adherent cells from marrow can serve as a longlasting precursor cells for bone, cartilage, and lung in irradiated mice. Proc. Natl. Acad. Sci. USA 92:4857-61

Petersen SE, Bowen WC, Patrene KD, Mars WM, Sullivan AK, et al. 1999. Bone marrow as a potential source of hepatic oval cells. Science 284:1168-70

Pittenger MF, Mackay AM, Beck SC, Jaiswal RK, Douglas R, et al. 1999. Multilineage potential of adult human mesenchymal stem cells. Science 284:143-47

Ray J, Peterson DA, Schinstine M, Gage FH. 1993. Proliferation, differentiation, and longterm culture of primary hippocampal neurons. Proc. Natl. Acad. Sci. USA 90:3602-8

Reynolds BA, Weiss S, 1992. Generation of neurons and astrocytes from isolated cells of the adult mammalian central nervous system. Science 255:1707-10

Reynolds BA, Weiss S, 1996. Clonal and population analyses demonstrate that an EGFresponsive mammalian embryonic CNS precursor is a stem cell. Dev. Biol. 175:1-13

Richards LJ, Kilpatrick TJ, Bartlett PF. 1992. De novo generation of neuronal cells from the adult mouse brain. Proc. Natl. Acad. Sci. USA 89:8591-95

Seale JR, Varma S, Swirsky DM, Pandolfi PP, Goldman JM, et al. 1996. Quantification of PML-RAR alpha transcripts in acute promyelocytic leukaemia: explanation for the lack of sensitivity of RT-PCR for the detection of minimal residual disease and induction of the leukaemia-specific mRNA by alpha interferon. Br. J. Haematol. 95:95101

Shah NM, Anderson DJ. 1997. Integration of multiple instructive cues by neural crest stem cells reveals cell-intrinsic biases in relative growth factor responsiveness. Proc. Natl. Acad. Sci. USA 94:11369-74

Shah NM, Groves A, Anderson DJ. 1996. Alternative neural crest cell fates are instructively promoted by TGF $\beta$ superfamily members. Cell 85:331-43

Shah NM, Marchionni MA, Isaacs I, Stroobant PW, Anderson DJ. 1994. Glial growth factor restricts mammalian neural crest cells to a glial fate. Cell 77:349-60

Shizuru JA, Jerabek L, Edwards CT, Weissman IL. 1996. Transplantation of purified hematopoietic stem cells: requirements for overcoming the barriers of allogeneic engraftment. Biol. Blood Marrow Transplant. 2:3-14

Shizuru JA, Weissman IL, Kernoff R, Masek M, Scheffold YC. 2000. Purified hematopoietic stem cell grafts induce tolerance to alloantigens and can mediate positive and negative T cell selection. Proc. Natl. Acad. Sci. USA 97:9555-60

Snyder EY. 1994. Grafting immortalized neurons to the CNS. Curr. Opin. Neurobiol. 4:742-51

Spangrude GJ, Heimfeld S, Weissman IL. 1988. Purification and characterization of mouse hematopoietic stem cells. Science 241:58-62

Stemple DL, Anderson DJ. 1992. Isolation of a stem cell for neurons and glia from the mammalian neural crest. Cell 71:973-85

Temple S, Alvarez-Buylla A. 1999. Stem cells in the adult mammalian central nervous system. Curr. Opin. Neurobiol. 9:135-41

Temple S, Davis AA. 1994. Isolated rat cortical progenitor cells are maintained in division in vitro by membrane-associated factors. $D e$ velopment 120:999-1008

Theise ND, Badve S, Saxena R, Henegariu $\mathrm{O}$, Sell S, et al. 2000a. Derivation of hepatocytes from bone marrow cells in mice after radiation-induced myeloablation. Нераtology 31:235-40

Theise ND, Nimmakayalu M, Gardner R, Lltei PB, Morgan G, et al. 2000b. Liver from bone marrow in humans. Hepatology 32:11-16 
Till J, McCulloch E. 1961. A direct measurement of the radiation sensitivity of normal mouse bone marrow cells. Radiat. Res. 14:1419-30

Traver D, Akashi K, Manz M, Merad M, Miyamoto T, et al. 2000. Development of CD8 $\alpha$-positive dendritic cells from a common myeloid progenitor. Science 290:215254

Tsukamoto A, Weissman IL, Chen B, DiGiusto D, Baum C, et al. 1995. Phenotypic and functional analysis of hematopoietic stem cells in mouse and human. In Hematopoietic Stem Cells: Biology and Therapeutic Applications, ed. D Levitt, R Mertelsmann, pp. 85-124. New York: Dekker

Uchida N, Buck DW, Dongping H, Reitsma MJ, Masek M, et al. 2000. Direct isolation of human central nervous system stem cells. Proc. Natl. Acad. Sci. USA 97:1472025

Uchida N, Tsukamoto A, He D, Friera AM, Scollay R, Weissman IL. 1998. High doses of purified stem cells cause early hematopoietic recovery in syngeneic and allogeneic hosts. J. Clin. Invest. 101:961-66

Uchida N, Weissman IL. 1992. Searching for hematopoietic stem cells: evidence that Thy$1.1^{\text {lo }} \mathrm{Lin}^{-} \mathrm{Sca}-1^{+}$cells are the only stem cells in C57BL/Ka-Thy-1.1 bone marrow. J. Exp. Med. 175:175-84

Weissman IL. 2000a. Stem cells: units of de- velopment, units of regeneration, and units in evolution. Cell 100:157-68

Weissman IL. 2000b. Translating stem and progenitor cell biology to the clinic: barriers and opportunities. Science 287:1442-46

White PM, Anderson DJ. 1999. In vivo transplantation of mammalian neural crest cells into chick hosts reveals a new autonomic sublineage restriction. Development 126:435163

White PM, Morrison SJ, Orimoto K, Kubu CJ, Verdi JM, et al. 2001. Neural crest stem cells undergo cell-intrinsic developmental changes in sensitivity to instructive differentiation signals. Neuron 29:57-71

Whitlock CA, Tidmarsh GF, Muller-Sieburg C, Weissman IL. 1987. Bone marrow stromal cells with lymphopoietic activity express high levels of a pre-B neoplasia-associated molecule. Cell 48:1009-21

Wright DE, Cheshier SH, Wagers AJ, Randall TD, Christensen JL, Weissman IL. 2001. Cyclophosphamide/granulocyte colony-stimulating factor causes selective mobilization of bone marrow hematopoietic stem cells into the blood after M-phase of the cell cycle. Blood 97:2278-85

Wu A, Till J, Siminovitch L, McCulloch E. 1968. Cytological evidence for a relationship between normal hematopoietic colonyforming cells and cells of the lymphoid system. J. Exp. Med. 127:455-67 


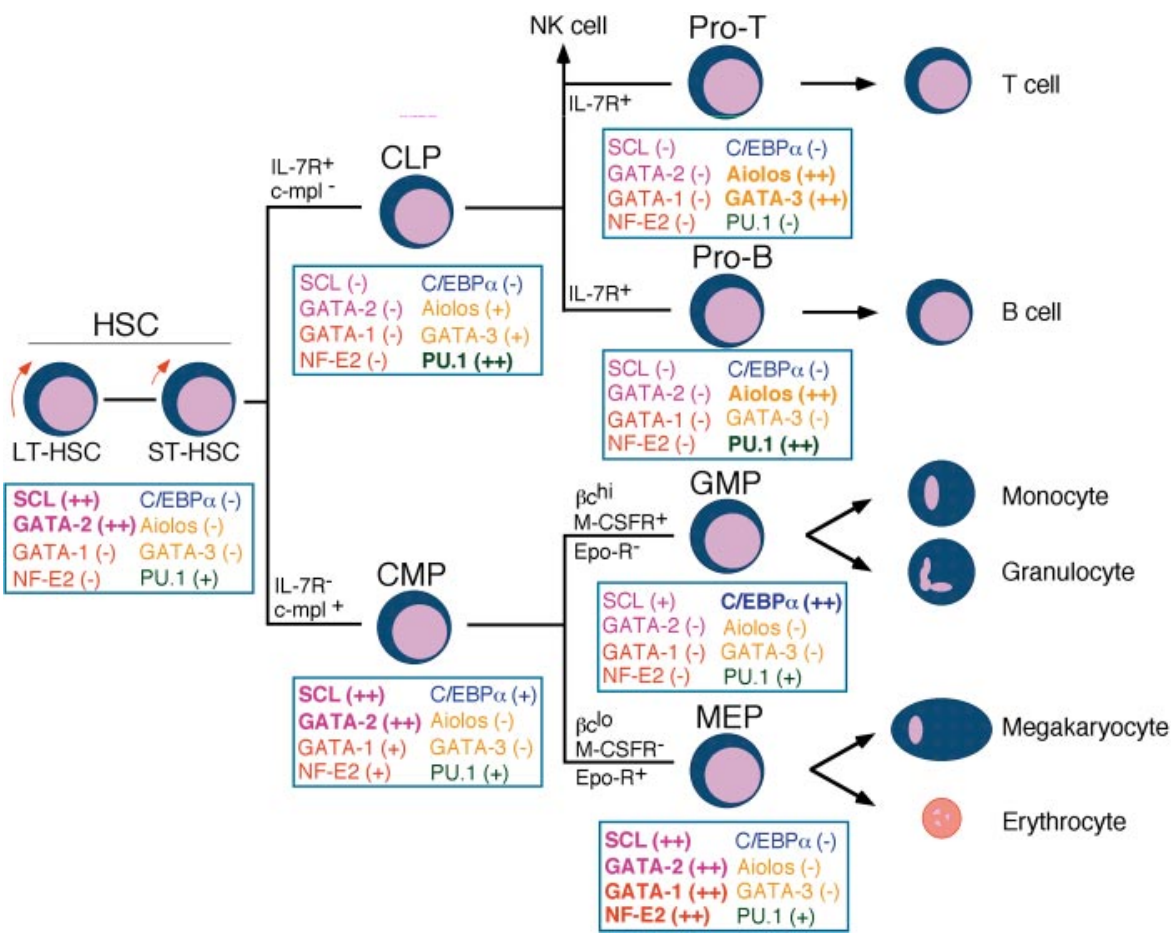

Figure 1 Proposed model of major hematopoietic maturation pathways from HSC. Longterm HSC (LT-HSC) give rise to short-term (ST) HSC. We propose that ST-HSC give rise to at least CLP, which can form all cells of the lymphoid lineage, and CMP, which can differentiate into either GMP or MEP, which form the cells of the granulocyte/macrophage or megakaryocyte/erythroid lineages, respectively. The three myeloid progenitor subsets should make up the vast majority of myeloid progenitor activity in steady-state bone marrow because the Sca- $1^{-}$c-kit ${ }^{+}$fraction, which is composed of GMP, MEP, and CMP, and the Sca- ${ }^{+}$c-kit ${ }^{+}$ HSC fraction, were estimated to contain $\sim 98 \%$ of myeloid colony-forming activity within the Lin- IL-7R $\alpha$ - fraction (data not shown). (From Nature 404: 193-97, 2000, with permission) 


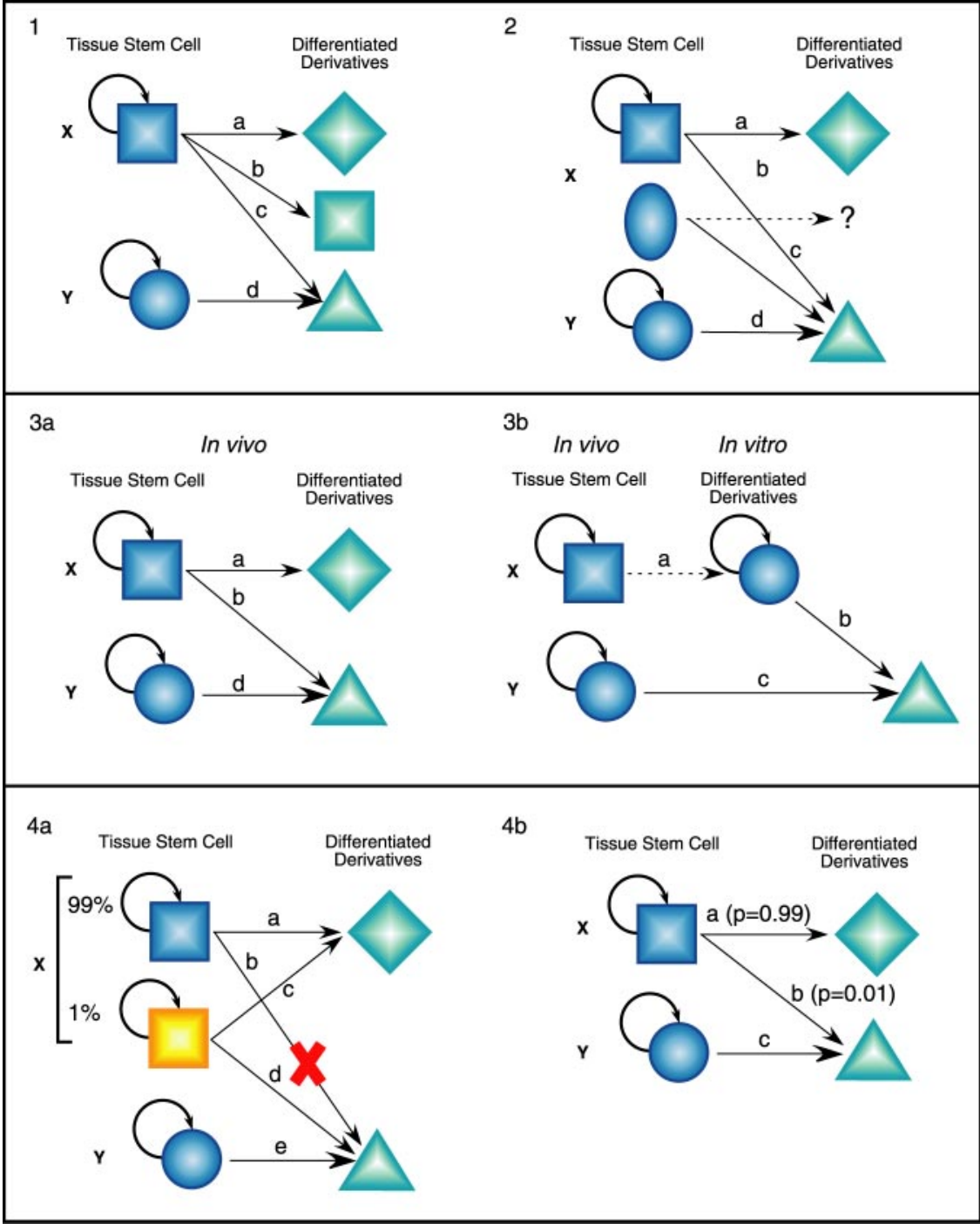

Figure 2 See legend on next page 
Figure 2 (See figure on previous page) (opposite page) Unresolved issues about transdifferentiation. (1) Extent of phenotypic conversion. In this and in all of the following examples, tissue $\mathrm{X}$ contains a stem cell (square) that ordinarily differentiates into a cell type (diamond) appropriate for tissue (a), whereas tissue Y contains another stem cell (circle) that ordinarily differentiates into a different cell type (triangle) appropriate for that tissue (d). (c) Complete conversion of stem cell X into the differentiated cell type characteristic of tissue Y (triangle) might occur upon transplantation. (b) Transplanted stem cell X might also have differentiated to a cell expressing some phenotypic markers characteristic of tissue Y (shaded square), but did not actually undergo complete differentiation to the functional cell type characteristic of tissue Y (shaded triangle). Current experiments often do no distinguish these alternative possibilities. (2) Origin of transdifferentiating cells. (a) Tissue X contains a stem cell (square) that normally generates cell types characteristic of that tissue (diamond). (b) Upon transplantation of a mixed population of cells from tissue X, one type of stem cell (square) might transdifferentiate to cells characteristic of tissue Y (shaded triangle). (c) Upon transplantation of a mixed population of cells from tissue $X$, the differentiated cell type characteristic of tissue Y (triangle) might derive not from the stem cell for tissue $\mathrm{X}$ (square), but from another, unknown progenitor cell present in the mixed population (oval). (d) Tissue Y contains stem cells that normally generate cell types characteristic of that tissue (triangle). (3) Transdifferentiation requires prior reprogramming in vitro. (3a) In vivo, stem cell $\mathrm{X}$ does not have the capacity to differentiate to cells characteristic of tissue $\mathrm{Y}(\mathrm{b})$. ( $3 b$ ) In vitro, stem cell $\mathrm{X}$ undergoes reprogramming (a) to acquire the capacity to differentiate to cell types characteristic of tissue Y (b). (4) Significance of low-frequency of phenotypic conversion. In both cases, only $1 \%$ of the cells in an isolated stem cell population from tissue $\mathrm{X}$ undergo conversion to cell types characteristic of tissue Y upon transplantation. (4a) The low frequency of the event reflects a minority subpopulation of stem cells within the isolated population (gold square) that has the capacity to transdifferentiate (d); the majority of the isolated stem cells (open square) do not have the capacity to transdifferentiate (b). (4b) The isolated stem cell population from tissue $\mathrm{X}$ is homogeneous (open square), but these cells undergo transdifferentiation with a very low probability $(\mathrm{b}, \mathrm{p}=0.01)$ and $99 \%$ of the time do not undergo such transdifferentiation (a). 
Rolume 17, 2001
Veview of Cell and Developmental Biology

\section{CONTENTS}

Chemical AND Biological StRATEgIES FOR ENGINEERING CELL Surface GlyCosylation, Eliana Saxon and Carolyn Bertozzi

THROMBOSPONDINS: MULTIFUNCTIONAL REGULATORS OF CELL INTERACTIONS, Josephine C. Adams

SALMONELLA INTERACTIONS WITH HOST CELLS: TYPE III SECRETION AT WORK, Jorge E. Galán

PATTERNing Mechanisms CONTROLling VERTEBRATE LimB DEVELOPMENT, Javier Capdevila and Juan Carlos Izpisúa Belmonte

IDENTIFICATION OF SELF THROUGH TwO-DiMENSIONAL CHEMISTRY AND SYNAPSES, Michael L. Dustin, Shannon K Bromley, Mark M. Davis, and Cheng $\mathrm{Zhu}$

Polarized Cell Growth In Higher Plants, Peter Hepler, L. Vidali, and A. Cheung

BOUNDARIES IN DEVELOPMENT: FORMATION AND FUNCTION, Kenneth D. Irvine and Cordelia Rauskolb

Molecular BASES OF CiRCADIAN RHYTHMS, Stacey L. Harmer, Satchidananda Panda, and Steve A. Kay

EARLY EYE DEVELOPMENT IN VERTEBRATES, Robert L. Chow and Richard A. Lang

RNP LOCALIZATION AND TRANSPORT IN YEAST, Pascal Chartrand, Robert H. Singer, and Roy M. Long

VERTEBRATE SOMITOGENESIS, Olivier Pourquié

ANIMAL CELl CyTOKINESIS, Michael Glotzer

Stem And PRogenitor Cells: Origins, Phenotypes, Lineage COMMITMENTS, AND TRANSDIFFERENTIATIONS, Irving L. Weissman, David J. Anderson, and Fred Gage

RECENT AdVANCES IN CHEMICAL APPROACHES to THE STUdy OF BIOLOGICAL SYSTEMS, Michael A. Shogren-Knaak, Peter J. Alaimo, and Kevan M. Shokat

EMbryo-Derived Stem Cells: Of Mice AND Men, Austin G. Smith 
How Matrix Metalloproteinases Regulate Cell Behavior, Mark D. Sternlicht and Zena Werb

BIOLOGICAL BASKET WEAVING: FORMATION AND FUNCTION OF

CLATHRIN-COATED VeSICLES, Frances M. Brodsky, Chih-Ying Chen, Christine Knuehl, Mhairi C. Towler, and Diane E. Wakeham

GetTING THE Message ACROSS: THE INTRACELlulaR LOCALIZATION OF mRNAS IN HIGHER EUKARYOTES, Isabel M. Palacios and Daniel St. Johnston

CELlular FunCTION OF PHOSPHOINOSITIDE 3-KinASES:

IMPLICATIONS FOR DEVELOPMENT, IMMUNITY, HOMEOSTASIS, AND CANCER, Roy Katso, Klaus Okkenhaug, Khatereh Ahmadi, Sarah White, John Timms, and Michael D. Waterfield

Control of EArly SeEd Development, Adbul M. Chaudhury, Anna Koltunow, Thomas Payne, Ming Luo, Mathew R. Tucker, E. S. Dennis, and W. J. Peacock

PEROXISOME BIOGENeSIS, P. Edward Purdue and Paul B. Lazarow

The Molecular Basis of Sister-Chromatid CoHESION, Janice Y. Lee and Terry L. Orr-Weaver

LEFT-RIGHT ASYMMETRY DETERMINATION IN VERTEBRATES, Mark Mercola and Michael Levin

INDEXES

Subject Index

Cumulative Index of Contributing Authors, Volumes 13-17

Cumulative Index of Chapter Titles, Volumes 13-17

\section{ERRATA}

An online log of corrections to Annual Review of Cell and Developmental

Biology chapters may be found http://cellbio.AnnualReviews.org/errata.shtml 